\title{
Keywords
}

On-Line Experiments; Language Bursts; Transcription; Translation; Specific Learning Disabilities in Written Language (SLDS-WL) 
The current study aims to advance understanding of writing processes in students who have been diagnosed with specific learning disabilities in written language (SLDs-WL). To do so, the study was designed utilizing current research findings, paradigms, and tools for studying writing and SLDs-WL, as explained next.

\section{Processes involved in writing}

Writing involves complex cognitive, linguistic, and motor activities, which some have argued require decades to master (Kellogg, 2008). Models of writing distinguish between translation (generating ideas and mapping ideas onto written language) and transcription (producing with working memory support written words, sentences, and text by either forming letters with a writing tool or selecting letters on a keyboard) (Berninger \& Swanson, 1994; Hayes \& Berninger, 2014). Although the outcomes of transcribing can be observed in the letter formation/selection and spelling of writers, translation processes are internal and not directly observable. However, innovative methodologies such as on-line experiments have been developed to support the study of internal translation processes and their relationships to transcription in adults and children (e.g., Alamargot, Chesnet, Dansac, \& Ros, 2006; Alamargot, Dansac, Chesnet, \& Fayol, 2007; Alves, Branco, Castro, \& Olive, 2012; Alves, Castro, \& Olive, 2011; Alves \& Limpo, 2015; Alves, Limpo, Fidalgo, Carvalhais, Pereira, \& Castro, 2016; Leijten \& Van Waes, 2013; Van Waes \& Schellens, 2003).

\section{Specific learning disabilities in written language (SLDs-WL)}

A few studies employing on-line experiments have focused on students with specific kinds of learning disabilities (SLDs), such as specific language impairment (Connelly, Dockrell, Walter, \& Critten, 2012) or dyslexia (Sumner, Connelly, \& Barnett, 2013, 2014, 2016) or dyslexia and dysgraphia (Beers, Mickail, Abbott, \& Berninger, 2017). Writers with any of these SLDs may experience writing difficulties (cf. Connelly \& Dockrell, 2016). Family genetic/phenotype and brain imaging research have shown that students with SLDs-WL may have dysgraphia (impairments in handwriting) or dyslexia (impairments in spelling along with deficits in decoding) (Berninger, 2015). Such hallmark transcription disabilities in handwriting or spelling that interfere with the production of letters and written words, respectively, may in turn affect the ability to translate one's thoughts into sentences and longer texts (Berninger \& Hayes, 2012; Christensen, 2005; Limpo \& Alves, 2013). For example, transcription difficulties have been shown to tax working memory resources, influencing writing fluency and text quality (Bourdin \& Fayol, 1994; Olive, Kellogg, \& Piolat, 2008).

In typically developing writers "lower level" aspects of graphomotor production become increasingly automatized with practice, enabling writers to devote cognitive resources to "higher level" processes of writing, which can be employed in parallel with transcription (Alamargot et al., 2007). In students with dysgraphia or dyslexia such graphomotor production processes may not become automatized and as a result the students often exhibit slower writing production and shorter texts overall (Berninger, Rutberg et al., 2006). However, for students with dyslexia, slower writing production may result not from slower 
handwriting speed, but from more frequent and longer pauses during writing (hesitations or breaks) than age-matched peers (Sumner et al., 2013). During those pauses, students with dyslexia may be searching for and retrieving specific letters in less efficient ways than typically-developing students. Overall, shorter texts (Beers, Mickail, Abbott, \& Berninger, 2017; Puranik, Lombardino, \& Altmann, 2007) and texts rated lower in quality (Coleman, Gregg, McLain, \& Bellair, 2009) tend to be hallmarks of students with impaired handwriting skills.

Students with dyslexia often have difficulties with spelling in addition to reading, further constraining transcription processes (Sumner, Connelly, \& Barnett, 2014). These poor spelling skills have been described as creating a "double disadvantage" for students with dyslexia when writing for two reasons (Connelly \& Dockrell, 2016). First, difficulties with spelling have been shown to lead to reduced lexical diversity in written texts (as compared to orally produced texts), because students with dyslexia are more likely to choose words they believe they can spell (Sumner et al., 2016). Second, their less-accurate phonological and orthographic representations lead to slower, more cognitively costly written word spelling processes, consequently drawing upon limited resources that could be used elsewhere in the writing process (Berninger et al., 2008).

Dysgraphia, a disability marked by impaired writing of letters by hand, is distinct from dyslexia in that word-level reading is not affected. Neuropsychological research has helped researchers differentiate between developmental dysgraphia and developmental motor coordination disabilities, demonstrating that dysgraphia manifests as specific deficits in legible and automatic handwriting from memory in students within the normal range of cognitive abilities. Recent research has shown that students with dysgraphia may also have difficulties with word-level spelling even though their primary deficit is in handwriting. Thus, students with dyslexia or dysgraphia have impairments in transcription skills that can interfere with higher order writing processes when composing. Yet currently in the United States, students are identified for special education services without consideration of evidence-based differential diagnosis of the nature of their SLD. Rather, low achievement alone or the failure to respond to intervention (RTI) may qualify them for these services. Yet neither low achievement on a single measure nor response to a single kind of intervention may be a valid way to diagnose an SLD-WL. Often reading, not writing, is emphasized during early intervention even though writing impairments may characterize SLDs-WL such as dysgraphia and dyslexia (see Berninger, 2015).

The focus of the current study was on persisting SLDs-WL despite early intervention in the primary grades. Of interest was persisting SLDs-WL during the upper elementary and middle school grades when school curricula often does not provide systematic instruction in handwriting, keyboarding, or spelling despite increases in the amount and complexity of writing required for school assignments. Moreover, although normed measures that provide benchmarks for comparing students with age or grade peers can provide very helpful information for identifying SLDs-WL and monitoring response to intervention, normed measures based on observable behavioral outcomes alone may not be sufficient. On-line experiments that support inferences about invisible but relevant processing underlying 
observable behavior may also provide valuable information for identifying and monitoring SLDs-WL and monitoring response to writing intervention.

Therefore, the current study employed both normed measures and on-line experimental methods. Normed measures were used as part of the ascertainment process and assignment to diagnostic groups and as part of assessing student responses to computerized writing lessons. For Research Aim 1, prior to beginning the computerized instruction and subsequent to completing it, students also participated in an on-line experiment of translation and transcription processes in writing. For Research Aim 2, students who qualified as typical written language learning controls completed the same on-line experiment.

\section{On-Line Experiment to Assess Writing Processes}

\section{Paradigm}

Measures such as language bursts (words composed in between pauses in text production), pauses in composing (both frequency and duration), and composing rates (generally words per minute) help illuminate how the translation processes of writing unfold in real time. Language bursts were first identified by Kaufer, Hayes, and Flower (1986), who observed that skilled writers generally produced writing in "bursts" of approximately 9 words, which would be followed by pauses of two seconds or more. In a series of additional studies, Hayes and colleagues have demonstrated relationships between language bursts and translation processes (Kaufer, Hayes, \& Flower, 1986; Chenoweth \& Hayes, 2001, 2003; Hayes \& Chenoweth, 2007).

For those with less automatic handwriting, transcription processes also influence language bursts. For example, Alves and Limpo (2015) found that as student writers developed increasingly automatized transcription, burst lengths increased, which were in turn related to increases in overall writing fluency and text quality. Alves et al. (2012) proposed that more efficient transcription skills contribute to longer bursts by easing the cognitive demands of writing, allowing writers to capture larger language segments when transcribing them. More recently, Alves et al. (2016) found evidence for a causal link between transcription skills and language bursts, as a 10-week intervention focusing on handwriting skills led to increases in overall writing fluency, including longer bursts, shorter pauses, and higher quality stories.

However, only two studies of language bursts and transcription processes have included students with specific language impairment (SLI), which affects both oral language development during the preschool and school years and writing development during the school years. Connelly, Dockrell, Walter, and Critten (2012) found that students with SLI, when compared to typically developing 11 year-olds, composed in shorter language bursts. Importantly, for students with SLI, handwriting fluency and spelling accuracy were predictors of their burst length. In another study (Author, 2017), students with dyslexia were compared with typically developing students in two writing modes (handwriting and keyboarding) on text product and process measures for narrative writing. In both transcription modes, students with dyslexia composed in shorter language bursts, with slower composing rates and with more spelling errors than their typically developing peers. 


\section{Genres}

Theorists view genres as socially constructed language practices serving specific social purposes (Halliday \& Hasan, 1985), each of which may differ in their linguistic features as well as their structural characteristics. In the course of schooling students encounter writing tasks in different genres, ranging from narrative (stories about others and personal stories) to expository (informative, compare and contrast, and persuasive essays). Expository writing is especially important for academic success during middle childhood and early adolescence (e.g., Berman \& Nir-Sagiv, 2007), yet some expository genres, namely persuasive essays, can present challenges at the level of ideas (presenting claims and reasons) and at the level of syntax (using more complex sentence structures). For example, Crowhurst and Piche (1979) concluded that "narration places fewest demands and argument greatest demands on writers to make use of their syntactic resources" (p. 107). Furthermore, relationships have been shown between syntactic complexity and text quality at the middle school level (Beers \& Nagy, 2009). Despite the importance of expository writing, few studies of students with SDLs-WL focus upon essay writing. Thus, for purposes of the current study persuasive essays were administered as part of the on-line experiment.

\section{Instructional Interventions for Transcription Disabilities}

Research has shown that students with SLDs-WL can learn to form letters via stylus or index finger on computer screens (Berninger, Nagy, Tanimoto, Thompson, \& Abbott, 2015). Research has also identified effective spelling instruction for students with SLDs-WL (Berninger, Nagy et al., 2015; Tanimoto, Thompson, Berninger, Nagy, \& Abbott, 2015; Wanzek, Vaughn, Wexler, Swanson, Edmonds, \& Kim, 2006). Currently two approaches are generally being used to assess the effectiveness of writing instruction for students with SLDs-WL. The first uses normed measures at pretest before intervention and again at posttest after intervention to evaluate whether significant improvement has occurred in reference to norms yoked to age or grade mates. This approach considers only the writing products in assessing the effectiveness of writing instruction or only behavioral measures of presumed underlying processes. The second uses curriculum based measurement to assess response to intervention (RTI) and is often performed at the beginning, middle, and end of the school year. Both of these RTI approaches assess writing products; neither assesses the internal processes unfolding in real time that lead to the writing products. The use of on-line experiments to assess cognitive processes underlying written language composition tasks offers a third approach that might supplement, rather than replace, these other approaches for assessing RTI. On-line tasks have promise for informing our understanding of the perplexing struggles that students with persisting SLDs-WL experience in learning to construct and produce written language during composition.

\section{Research Aims}

\section{Research Aim 1}

The first goal of this study was to evaluate the effects of an 18-session computerized writing instruction program upon the on-line translation processes and transcription products of students with persisting dyslexia or dysgraphia during composing. In the 18 lessons students 
received instruction in forming letters with styluses, spelling (with explicit instruction for English morphophonemic orthography), and composing expository texts by both stylus and keyboarding. In this within-participant design, the same students in grades 4 to 9 who met normed-referenced, research-supported criteria for diagnosis of persisting dyslexia or dysgraphia during middle childhood or early adolescence participated in the computerized intervention and completed the on-line experiment at pretest and posttest so that they could be compared to themselves before and after participating in an intervention that taught to all levels of written language and both transcription and translation processes close in time.

No group of students was held out of the lessons because the research aim was to evaluate whether the students showed significant change as a function of the lessons, as opposed to evaluating the effect of having no intervention or contrasting interventions. Given the participants' ongoing histories of consistently failing to respond to intervention in the current school year and in the past, the first step was to show that they could learn to respond to writing instruction and improve on normed-reference writing measures. Published research showed that they could improve on these measures (Berninger et al., 2015; Tanimoto et al., 2015). The second step, addressed in Research Aim 1, was to see if these students improved in their translation and transcription skills when writing longer, more complex texts (persuasive essays). The first hypothesis tested was that all participants would show gains in writing fluency and spelling skill as a result of the computerized instruction. More specifically, it was expected that students with SLDs-WL would exhibit increases in words per minute, average length of language bursts, and total words written overall. Additionally, it was expected that students would have fewer pauses per minute following the intervention, and would make fewer spelling errors in their texts. Also of interest, however, was whether the response to the intervention (RTI) was related to the nature of their diagnosed SLD-WL (dysgraphia or dyslexia) or mode of transcription (stylus or keyboarding). Based on meta-analyses of word processing showing that longer texts were composed when students were keyboarding (Goldberg, Russell, \& Cook, 2003; Morphy \& Graham, 2012), the hypothesis was tested that longer texts would be produced for keyboarding; and based on prior research showing that writers paused more often when keyboarding (van Waes \& Schellens, 2003), another hypothesis tested was that more pauses when keyboarding.

\section{Research Aim 2}

The second aim was to evaluate whether following instruction the performance of students with SLDs-WL on the on-line experimental tasks was comparable to that of typical control students without SLDs-WL who had completed the same on-line experimental tasks. Because on-line experiments do not have norms for age or grade peers to which students' performance can be compared, it was important to evaluate whether performance on the online tasks following intervention was comparable to that of students without SLDs-WL. Demonstrating such comparability would provide initial evidence that normalization might be possible despite prior persisting failure to respond to specialized instruction. Such a demonstration is educationally important because both dysgraphia and dyslexia have been shown to have a genetic basis though not the same genetic basis (Abbott, Raskind, Matsushita, Richards, Price, \& Berninger, 2017). 


\section{Method}

\section{Ascertainment of Participants}

Public school districts and one parochial school with diverse student populations were contacted and flyers were distributed through local schools announcing an opportunity to participate in research for upper elementary and middle school students in grades 4 to 9 with and without persisting written language disabilities affecting writing and reading. Interested parents contacted the principal investigator who answered any questions about the study and interviewed parents to determine whether the student was likely to have an SLD-WL. The interview included obtaining a detailed developmental history (to rule out developmental disabilities), an educational history (whether any learning problems were identified and if services were provided at school or out of school, and if so, for how long), a family history (including identifying family members with learning problems), and a medical history (to rule out medical, neurological, or neurogenetic disorders such as fragile-X or neurofibromatosis or PKU, a significant hearing loss or visual impairment, cerebral palsy or muscular dystrophy, spinal cord or brain injuries, substance abuse, psychiatric disorder diagnosis, epilepsy or other seizure disorders, etc.). Following the interview, if it was determined that the student was likely a typically developing language learner or had dyslexia or dysgraphia, consent from the parent and assent from the student was obtained for comprehensive assessment (described in next section) of the student at the research university in a large metropolitan city.

During the comprehensive assessment of the student, the parents completed additional questionnaires about developmental, educational, family, and medical histories using evidence-based parent checklists about language, social-emotional behavior, attention and executive functions, and sensorimotor skills. The student was invited to participate in one or more studies in the multidisciplinary learning disabilities center if the interview, questionnaire, family history and comprehensive assessment provided converging evidence to: (a) rule out a developmental disability or medical condition that could explain learning problems rather than SLD-WL; (b) document that the SLD had been identified earlier in schooling and services were provided at or outside school, and that the student had a longstanding history of failing to respond to the intervention; (c) demonstrated proficiency in English; and (d) supported the differential diagnosis of typical language learner, dysgraphia, or dyslexia. One of these study opportunities was a computerized instruction intervention. Another opportunity was the on-line experiment. Students could participate in one of the studies without participating in the others. Research Aim 1 was based on analyses of students who participated in both of these studies. Research Aim 2 included students who participated in the intervention and those who participated only in on-line experiment (the typical language learning controls). The recruitment flyers, the phone interview procedures, the assessment battery, the intervention, and the on-line experiment were approved by the Institutional Review Board at the university where the research was conducted and were in compliance with the professional standards of the American Psychological Association. 


\section{Assessment Measures for Differential Diagnosis}

To assess handwriting with pencil and paper, three measures were given. The alphabet 15 seconds task requires that the alphabet be written from memory in order and in manuscript (unjoined letters) that others can recognize and as quickly as possible. The raw score is the number of legible letters in correct alphabetic order during first 15 seconds, which can be converted to a $z$-score $(M=0, S D=1)$ based on research norms for grade (inter-rater reliability .97). Students also completed the Detailed Assessment of Speed of Handwriting (DASH) Best and Fast (Barnett, Henderson, Scheib, \& Schulz, 2007). The task is to copy a sentence which includes all the letters of the alphabet—first in one's best handwriting and then in one's fastest writing, using one's usual handwriting - either manuscript (unconnected) or cursive (connected) or a combination of these. In the current study, two testers reviewed all the scored handwritten measures to reach consensus on scoring; raw scores are converted into scaled scores $(M=10, S D=3)$.

Three spelling measures were given: Word Scrambles of the Test of Orthographic Competence (TOC) (Mather, Roberts, Hammill, \& Allen, 2008) for which students are asked to rearrange letters to create a correctly spelled word; the TOC Homophone Choice (ages 9 to 12,) or Word Choice (ages 13 to 16) (test-retest reliability .72 to .75) for which students are asked to identify a correct spelling for a specific word among foils pronounced the same but whose spelling does not correspond to a real word; and the Wechsler Individual

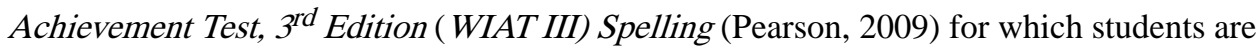
asked to spell (in writing) dictated real words, pronounced alone, then in a sentence, and then alone (test-retest reliability .92). The raw score on all TOC subtests was converted to a scaled score $(M=10, S D=3)$, whereas the raw score on WIAT III Spelling was transformed into a standard score $(M=100, S D=15)$.

To assess accuracy of oral reading of real and pseudowords, the Woodcock-Johnson Psychoeducational Battery 3rd Edition (WJ III, Woodcock et al., 2001) Word Identification subtest (test-retest reliability .95), and the WJ III Word Attack subtest (test-retest reliabilities .73 to .81 ) were given. To assess accurate and fast oral word reading and decoding, the Test of Word Reading Efficiency (TOWRE) (Torgesen, Wagner, \& Rashotte, 1999) Sight Word Efficiency Test (test-retest reliability is .91) and Pseudoword Efficiency Test (test-retest reliability .90) were also given. Finally, to assess silent word reading accuracy and rate, the Test of Silent Word Reading Fluency (TOSWRF) (Mather, Hammill, Allen, \& Roberts, 2004) (test-retest reliability is .92) was given, with students attempting to mark the word boundaries in a series of letters arranged in rows.

\section{Differential Diagnosis Procedures}

The assessment battery, based on over two decades of interdisciplinary research on normal variation in typical oral and written language development and specific learning disabilities in oral and written language learning disabilities, was designed for instructionally relevant differential diagnosis of specific learning disabilities in written language (SLD-WL). A minimum standard score of $80(-11 / 3 \mathrm{SD}$ which is in the low average range at the lower limit of the normal range) on WISC IV Verbal Comprehension Index (VCI) (Wechsler, 2003) was required for participation. This criterion ensured that no participant fell outside 
the normal range in translating cognitions into oral language and that problems in written language were specific to transcription (handwriting and/or spelling) or reading, and not to a disability in cognition or translation not requiring written transcription. However, almost all VCI standard scores were in the average range (90 to 109), above average range (110 to 119 ), or superior to very superior range (120 to 140 and above) of the normal distribution, which collectively is where $75 \%$ of the school-age population falls.

Diagnosis was never based on a single measure; rather profiles were constructed with multiple normed measures; students had to meet evidence-based criteria on at least two of these for SLDs-WL (see Berninger, Richards, \& Abbott, 2015). To qualify for a dysgraphia diagnosis, the evidence-based criteria used were scores below -2/3 SD (90 standard score or 8 scaled score) on two handwriting measures and parent reported current and past history of persisting handwriting problems. To qualify for a dyslexia diagnosis, the evidence-based criteria used were scores below -2/3 SD ( 90 standard score or 8 scaled score) on two or more spelling and word reading measures, which were also at least a standard deviation below scores on the Wechsler Verbal Comprehension Index, and parent reported current and past history of persisting word reading/decoding and spelling/encoding problems. To qualify for a typical language learner diagnosis, all writing and reading measures had to be at least in the average range (at or above $-2 / 3 \mathrm{SD}$ ) and there could be no parent reported current or past history of writing or reading problems.

\section{Sample Characteristics}

Students with dysgraphia-For those who met the research criterion for dysgraphia, their mean age was 140.00 months $(S D=11.42)$ and their mean WISC 4 Verbal Comprehension Index was $110.67(\mathrm{SD}=16.13)$ in the above average range. Their mean scores on the handwriting measures were as follows: Alphabet 15 seconds, $-1.78 z(S D=.71)$, DASH Copy Best, 8.11 ( $S D=3.51$ ), and DASH Copy Fast, 5.89 ( $S D=2.85$ ). Their mean scores on spelling measures were as follows: TOC Word Scrambles, 9.83 (SD=3.88), TOC Homophone/Word Choice, 11.00 (3.24), TOC Sight Spelling, 10.17 (3.01), and WIAT III Spelling, 98.83 ( $\mathrm{SD}=20.71$ ). For the reading measures, their mean score for the WJIII Word Identification was 111.67 ( $\mathrm{SD}=11.44$ ) and for the Word Attack test the mean was 107.78 $(\mathrm{SD}=12.53)$. On the Test of Word Reading Efficiency (TOWRE) the mean score was 109.83 ( $S D=16.36$ ), for the Pseudoword Efficiency Test the mean was 106.17 ( $S D=18.40)$, and for the Test of Silent Word Reading Fluency (TOSWRF) the mean was 100.50 ( $S D=14.93$ ).

Students with dyslexia-For those who met the research criterion for dyslexia, their mean age was 144.70 months $(S D=12.45)$ and their mean WISC 4 Verbal Comprehension Index was $115.90(S D=12.87)$ in the above average range. Their mean scores on the spelling measures were as follows: TOC Word Scrambles, 8.10 ( $S D=1.21)$, TOC Word Choice, 8.89 ( $S D=2.96$ ), TOC Sight Spelling, 7.300 ( $\mathrm{SD}=2.47$ ), and WIAT III Spelling, 83.65 ( $S D=14.45$ ). Their mean scores on the handwriting measures were as follows: Alphabet 15 seconds, $-1.57 z$ ( $S D=.77)$, DASH Copy Best, ( $S D=8.40)$, and DASH Copy Fast, 6.00 $(S D=2.96)$. Consistent with the cascading levels of language impairment in students with written language disabilities (Berninger, Richards et al., 2015), they were impaired on average in handwriting as well as word spelling, although individuals varied in relative 
levels of impairment in each of these transcription skills. For the reading measures, the mean score for the WJIII Word Identification was $95.90(\mathrm{SD}=8.86)$ and for the Word Attack test the mean was 93.50 ( $\mathrm{SD}=7.71$ ). On the Test of Word Reading Efficiency (TOWRE) the mean score was 93.50 ( $S D=11.99$ ), for the Pseudoword Efficiency Test the mean was 84.30 ( $S D=10.55$ ), and for the Test of Silent Word Reading Fluency (TOSWRF) the mean was $90.55(S D=9.86)$.

Additionally, all of their parents reported in the questionnaires that the problems with handwriting or word spelling/reading were observed first in kindergarten or first grade and had persisted throughout the early grades despite special help at school and in some cases outside school as well and continued during the upper elementary or middle school grades.

For those who met the research criterion for dyslexia, their mean age was 144.70 months $(S D=12.45)$ and their mean WISC 4 Verbal Comprehension Index was $115.90(S D=12.87)$ in the above average range. Their mean scores on the spelling measures were as follows: TOC Word Scrambles, 8.10 ( $S D=1.21)$, TOC Word Choice, 8.89 ( $S D=2.96)$, TOC Sight Spelling, 7.300 (SD=2.47), and WIAT III Spelling, 83.65 ( $S D=14.45)$. Their mean scores on the handwriting measures were as follows: Alphabet 15 seconds, $-1.57 z(S D=.77), D A S H$ Copy Best, ( $S D=8.40)$, and DASH Copy Fast, 6.00 ( $S D=2.96)$. Consistent with the cascading levels of language impairment in students with written language disabilities (Berninger, Richards et al., 2015), they were impaired on average in handwriting as well as word spelling, although individuals varied in relative levels of impairment in each of these transcription skills. For the reading measures, the mean score for the WJIII Word Identification was $95.90(\mathrm{SD}=8.86)$ and for the Word Attack test the mean was 93.50 (SD=7.71). On the Test of Word Reading Efficiency (TOWRE) the mean score was 93.50 ( $S D=11.99$ ), for the Pseudoword Efficiency Test the mean was 84.30 ( $S D=10.55$ ), and for the Test of Silent Word Reading Fluency (TOSWRF) the mean was 90.55 SD=9.86).

For those who met the research criterion for typical language learner, their mean age was 149.20 months $(S D=18.07)$ and their mean WISC 4 Verbal Comprehension Index was 112.50 ( $S D=11.81)$ in the above average range. All their writing and reading skills fell in the average range but above the mean and parents reported that the students never had any writing or reading problems since entering kindergarten.

\section{Parental level of education, ethnicity, grade/age of participants-For both}

Research Aim 1 and Research Aim 2, almost all the parents (mothers and fathers) of participating students had completed a college degree or more than a college degree. The ethnicity of the participants with and without SLDs-WL was typical of the community from which they were recruited. About three-fourths were European American and the others were from a single or mixed non-European ethnic background. Of the 18 qualifying for the dysgraphia group, 15 were boys and 3 were girls. Of the 20 qualifying for the dyslexia group, 15 were boys and 5 girls. Of the 15 qualifying for typical language learning control, 9 were males and 6 were females. For all three diagnostic groups grade level (mode end of fifth or beginning of sixth) and age (mean ages ranging from 12 years 5 months to 11 years 5 months) were similar. Standard scores on achievement measures were not necessarily higher for the older students in higher grades. Patterns (profiles) of scores rather than a single score 
on achievement measure or age or grade defined the diagnostic groups (see Berninger, Richards et al., 2015). For example, the typical controls were above the mean on all mean achievement measures, but the dysgraphia group was below the mean only on all handwriting measures and one spelling measure and the dyslexia group was below the mean on all achievement measures in the assessment battery.

\section{Computerized Writing Lessons}

The intervention consisted of 18 lessons each of which lasted approximately two hours. In each session students completed three sets of learning activities for handwriting, spelling, and composing. Unlike much specialized instruction that consists of explicit instruction on a single target skill such as phonemic awareness or phonological decoding, the lessons were organized by cascading levels of language, beginning with subword letter production, followed by word spelling, and ending with syntax and text level composing. Learning activities were completed close in time to create connections among components of the functional writing system.

Oral instruction was provided via earphones and written instruction via visual language displays on screen. Frequent feedback was provided by the computer program regarding correct responses often item by item and at the end of most learning activities for the student to record on their response to instruction (RTI) form so students and teachers could monitor their progress within and across lessons more frequently than ordinarily is possible in the classroom.

Each lesson began with a five-step handwriting warm-up for both lower case manuscript (unjoined letters) and lower case cursive letters (letters with connecting strokes) in each lesson. Step 1 was observing the visual motion of a letter forming through animation (visual motion). Step 2 was forming a letter with a stylus or finger while keeping the strokes within the contour around the letter displayed on the screen (kinesthetic feedback and grapho-motor control). Step 3 was copying the displayed letter (coordinating the mind's eye and hand). Step 4 was writing from memory a letter named (dictated) by the computer teacher through earphones but not displayed (associating the heard letter name with grapho-motor output plan). Step 5 was writing the letter that came before or after a named letter dictated by the computer teacher (finding, accessing, and producing a letter in ordered alphabet series in long-term memory). Students alternated in using a stylus and using their finger to form the letters on the screen for steps 2 through 5. Upper case manuscript and cursive letters were also practiced using steps 1,2, and 3, which were then followed by an activity in which students were asked to use the capital letters to write the first letter of a sentence providedmanuscript capitals for sentences that appeared on the screen in manuscript format, and cursive capitals for sentences that appeared on the screen in cursive format.

Computerized learning activities for spelling, which also alternated between using styluses and fingers, emphasized strategies for learning to spell English morphophonemic orthography. These included: (a) coding (storing and processing) the sounds (phonology) in heard and spoken words, the letters in read and written words (orthography), and linking phonology and orthography through morphology (bases and prefixes and suffixes that transform bases); (b) cross-code matrices for teaching the alphabetic principle in the spelling 
direction (from phoneme to grapheme); (c) holding written words in the mind's eye while analyzing letter identity, letter position, and letter sequence in them; (d) finding orthographic, morphological, and phonological stress patterns in words; and (e) transforming words by adding morphemes, shortening them to create contractions, and lengthening them to create compounds.

Students engaged in computerized learning activities for composing sentences and longer texts at the end of each lesson. For these activities, students either pressed buttons, dragged words, or used a stylus or an attached keyboard. For example, learning activities focused upon how word order and use of functions words (without meaning of their own such as conjunctions, prepositions, pronouns, and articles) connect content words (nouns, verbs, adjectives, adverbs) at the syntax level together to create meaning. They also learned strategies for writing "the very next sentence" within a longer, evolving text. For the first six lessons they wrote personal narratives (about their life before, during, and after their school years, and about their families, communities, the world, and their personal interests). For the final twelve lessons they read source text in the content areas of the curriculum (math, history, or world geography and cultures), while they practiced taking notes and writing summaries.

\section{On-Line Writing Experiment}

Pretest-posttest design-Prior to the first computerized writing lesson, participants completed an initial (pretest) series of writing tasks for the on-line experiment, during which text process and product measures were collected. After completing the 18 lessons, participants first completed a follow-up assessment with normed writing measures for reports shared with parents and schools regarding students' response to the intervention in the research study. The normed measures, which control for differences in age or grade in assessed students, showed significant improvement in writing skills and are reported elsewhere (see Berninger, Nagy et al., 2015; Tanimoto et al., 2015). At issue for this article was whether significant improvement would also be observed on non-normed writing process and product measures, hence pretest-posttest on-line experimental results are reported for the students with SLDs-WL.

Procedures for on-line experiment-All participants composed texts by hand (using a stylus upon a digital tablet) and by keyboard. The investigator began by introducing the participant to the equipment and providing ample practice time with it until he or she became comfortable writing on the digital tablet and using the keyboard. Directions were then given to the participant, including the first writing topic. Participants wrote two persuasive essays, and were given up to 10 minutes to compose each text, (they could stop when they indicated they were finished or when 10 minutes expired). Across the study, writing modes and text prompts were counterbalanced, with half of the participants randomly assigned to the handwriting condition first and the other half assigned to the keyboarding condition first (no order effects were found). In both conditions students could view the writing prompt at the top of the screen. 
Topics-The topics were designed to be familiar to the students, and similar in level of challenge. To confirm the absence of topic effects, independent-samples $t$ tests were conducted at posttest to compare topics within writing modes (handwriting or keyboarding). For topic effects, there were no significant differences found for total writing time, total words composed, words composed per minute, average length of language bursts, or the percentage of spelling errors.

The topics for the persuasive essays at pretest were as follows:

Prompt 1: Is Writing Important? Why or Why Not?

One purpose of writing is to express your opinion, defend it, and persuade others to think like you do- to accept your opinion. The topic of this writing activity is to take a position on whether writing is important, explain why you think it is important or why you do not think it is important, and then defend your position (belief) and try to persuade others that you are right and to have the same position (belief).

Prompt 2: Schools Teach Printing or Cursive or Both?

One purpose of writing is to express your opinion, defend it, and persuade others to think like you do- to accept your opinion. The topic of this writing activity is to take a position on whether one kind of handwriting — printing or cursive-is more important. Explain why you think it is important or why you do not think it is important, and then defend your position (belief) and try to persuade others that you are right and to have same position (belief).

The topics for the persuasive essays at posttest were as follows:

Prompt 1: Is Math Important? Why or Why Not?

One purpose of writing is to express your opinion, defend it, and persuade others to think like you do- to accept your opinion. The topic of this writing activity is to take a position on whether math is important, explain why you think it is important or why you do not think it is important, and then defend your position (belief) and try to persuade others that you are right and to have the same position (belief).

Prompt 2: Schools Teach Computer Skills?

One purpose of writing is to express your opinion, defend it, and persuade others to think like you do- - to accept your opinion. The topic of this writing activity is to take a position on whether schools should teach computer skills in class, explain why you think it is important or why you do not think it is important, and then defend your position (belief) and try to persuade others that you are right and to have the same position (belief).

Apparatus and material-For data collection, a 21-inch Wacom tablet was used in conjunction with an HP laptop along with a peripheral (standard US QWERTY) keyboard for the typed portions of the study. The same digital tablet was used (after adjusting it to lay 
flat upon a table) to collect data during the handwriting by stylus sessions. For the data collected during the keyboarding sessions, Inputlog software was used (Leijten \& Van Waes, 2013). For the stylus sessions, Eye and Pen version 2.0.0-70 was used for data collection and extraction (Alamargot, Chesnet, Dansac, \& Ros, 2006). After initial extraction, the data were then entered into a database using IBM SPSS Statistics Version 19.0.0.1, 2010.

Text product and process measures were analyzed for both transcription modes. To calculate composing time, average pause length, and words produced when keyboarding, Inputlog software was used. For the stylus written texts, composing time, average pause length, and words produced were calculated by Eye and Pen software. Spelling errors during keyboarding were identified using both the spellcheck function in Microsoft Word and researchers' visual inspection. For the stylus written texts, spelling errors were identified by two researchers, with $20 \%$ analyzed by both to determine interrater reliability (greater than $95 \%)$.

Pauses in production and language bursts during on-line composing-Pauses in text production were identified using Eye and Pen (for stylus writing) and Inputlog (for keyboarding). A pause in production was operationalized as a period of time during which no writing was produced, having a minimum duration of two seconds. Although some have suggested that different pause thresholds should be used for keyboarding (e.g. van Waes \& Schellens, 2003), a two second threshold was selected based upon prior studies of pauses and language bursts, using this criterion in both studies of handwriting (Alves \& Limpo, 2015; Alves et al., 2016; Connelly et al., 2012) and studies of keyboarding (Alves et al., 2007; Alves et al., 2011; Hayes \& Chenoweth, 2006). Additionally, Alves et al. (2012) found that a pause threshold of two seconds was "sensitive to children's production rates and the involvement of high-level writing processes" (p. 394). After identifying pauses, language bursts were then calculated, with a burst operationalized as the number of words produced following pauses of two seconds or longer (with a minimum of one word produced). Inputlog and Eye and Pen software programs identified pauses, and language bursts were then calculated manually (by counting words produced in between pauses). Next, language burst lengths were averaged for each writing task. Language bursts were calculated by two researchers, with $20 \%$ analyzed by both to determine interrater reliability (greater than $90 \%)$.

\section{Results}

\section{Research Aim 1}

A mixed ANOVA with 2 (time-pretest and posttest) $\times 2$ (mode-stylus and keyboard) repeated measures and 2 independent group measures (diagnostic group-dyslexia and dysgraphia) was conducted to test for main effects of the computerized intervention (pretest; posttest), for differences across writing modes (handwriting; keyboarding), and to test for potential interactions before and after the intervention and writing mode. Mauchly's test of sphericity was not significant, so we report the unadjusted $F$-tests for the within-subjects effects and interaction tests. See Table 1 for the descriptive statistics. All time entries are given in seconds unless minutes are specified. For spelling, the table reports \% Spelling 
Errors (the number of spelling errors divided by the total number of words per text). Burst Length $=$ the average number of words produced per language burst. During process of analyzing these multiple outcomes it became apparent that not all the data were usable for one participant (male) with dyslexia, therefore the final analyses were based on 19 instead of 20 participants in this group.

Main effects for time (pretest vs. posttest)—Main effects for time were statistically significant for three of the seven product and process measures: total composing time, $F(1,36)=15.21, p<.001$, partial $\omega 2=.30$; words per minute, $F(1,36)=17.73, p<.001$, partial $\omega 2=.34$; and pauses per minute, $F(1,36)=6.74, p=.014$, partial $\omega 2=.16$. As the means indicate in Table 1, one product measure showed negative effects following the intervention (decrease in total time), while one product (words per minute) and one process measure (pauses per minute) showed positive effects following the intervention.

Additionally, two process measures (length of language bursts, $p=.062$, partial $\omega 2=.10$ ) and one product measure (percent of spelling errors, $p=.069$, partial $\omega 2=.09$ ) showed positive trends toward longer pauses and fewer spelling errors for essay writing.

Main effects for transcription mode (handwriting vs. keyboarding)—There were four significant main effects found for transcription mode. Three were for product measures (total words, total time, and percent of spelling errors), and one was for a process measure (pauses per minute). For total words $(F(1,36)=17.98, p<.001$, partial $\omega 2=.34)$, students wrote more words when using a keyboard. Similarly, students wrote for longer time periods when using a keyboard $(F(1,36)=111.15, p=.002$, partial $\omega 2=.24)$, and made fewer spelling errors $(F(1,36)=5.73, p=.022$, partial $\omega 2=.14)$. However, students made fewer pauses per minute when writing by stylus $(F(1,36)=116.49, p<.001$, partial $\omega 2=.77)$. There was a trend suggesting longer language bursts when writing by hand $(p=.068)$.

Significant interactions-For total words, total time, pauses per minute, and percent spelling errors there were significant time $\times$ mode interactions. For total words $(F(1,36)=$ $5.11, p=.030$, partial $\omega 2=.13)$ and total time $(F(1,36)=13.91, p=.001$, partial $\omega 2=.28)$, larger decreases were seen when writing by stylus at posttest than by keyboard. For pauses per minute, larger decreases were exhibited for keyboarding at posttest $(F(1,36)=6.50, p=$. 015 , partial $\omega 2=.16$ ), but for percent spelling errors, decreases were larger for stylus at posttest $(F(1,36)=6.92, p=.013$, partial $\omega 2=.17)$. There was one significant mode $\times$ group interaction, for total words $(F(1,36)=4.13, p=.050$, partial $\omega 2=.11)$, as students with dyslexia tended to write more than students with dysgraphia when writing by stylus, whereas students with dysgraphia tended to write more than students with dyslexia when writing by keyboard. Additionally, there was one significant intervention $\times$ mode $\times$ group interaction for total words $(F(1,36)=5.44, p=.026$, partial $\omega 2=.13)$. Students with dysgraphia wrote longer texts by keyboard and shorter texts by stylus following the intervention, and students with dyslexia wrote shorter texts in both modes at posttest.

\section{Research Aim 2}

The second analysis compared the students with dyslexia and the students with dysgraphia following the intervention with the group of typically developing students who had 
completed the same on-line experiment $(N=15)$. Two between participant ANOVAs were conducted, one comparing the dyslexia group with the typically developing group, and the other comparing the dysgraphia group with the typically developing group. See Table 1 for the descriptive data and Tables 2 and 3 for the ANOVA results for the Research Aim 2 analyses. Nonsignificant findings are supportive evidence that after intervention students with persisting SLDs-WL (dyslexia or dysgraphia) may reach levels of performance on the on-line experiment commensurate with typically developing students on the same on-line experiment measures.

In the first comparison (dyslexia vs. typically developing groups), there were two significant differences for writing by stylus, and three significant differences for keyboarding. When writing by stylus, typically developing students wrote more words overall, and made fewer spelling errors. For keyboarding, typically developing students wrote more words overall, made fewer spelling errors, and composed at a faster rate (more words per minute). There were no significant differences between the dyslexia and typical control groups for three transcription process measures (pause length, pauses per minute, and average length of language bursts). In the second comparison (dysgraphia vs. typically developing groups), there were two significant differences found for handwriting, and no significant differences found for any measure for keyboarding. For handwriting, typically developing students wrote more words overall, and wrote for a longer time. There were no significant differences between the dysgraphia and typical control groups for any of the transcription process measures (pause length, pauses per minute, average length of language burst), nor for words composed per minute.

\section{Discussion}

To evaluate the effects of the computerized writing lessons upon the on-line transcription and translation processes and transcription products of students with dyslexia and dysgraphia while composing essays, two sets of analyses were conducted on the same seven measured variables (total words, total time of composing, words per minute, percentage of spelling errors, average pause length, pauses per minute, and average burst length). To test for effects of the intervention upon the two participant groups across two writing modes (handwriting and keyboarding), a set of mixed $2 \times 2$ repeated measures $\times 2$ independent groups ANOVAs were conducted. The second set of between groups analyses compared the students with dyslexia or dysgraphia at posttest with typically developing students in the same grade range, to provide further insights into whether the intervention helped students compose more like students without SLDs-WL.

\section{First Hypotheses Tested and Significance}

The first set of hypotheses, that participants in both groups would show increases in writing fluency, spelling performance, length of language bursts, and total words written on writing tasks following the computerized intervention, was partially supported, with two unexpected results. In support of the hypothesis, significant main effects were found for increases in words composed per minute (rate of composing), with corresponding decreases in the average number of pauses per minute. 
Additionally, positive trends were found for average burst lengths and percent of spelling errors per text following the intervention. These results are consistent with Alves et al. (2016), who showed that promoting handwriting and spelling skills had effects upon transcription and translation processes such as language bursts and pauses. Although the effect sizes in this study were modest for these indicators of writing fluency (ranging from . 16 for pauses per minute to .34 for words per minute), improvements in writing fluency for students with transcription-related disabilities after only 18 sessions are notable. The intervention $\times$ mode interaction for pauses per minute indicates that the largest reduction in pause frequency was seen for keyboarding, suggesting that the intervention boosted aspects of keyboarding fluency in particular. This computerized intervention, targeting cascading levels of language from subword letter production to text-level composing, produced gains in writing fluency (with positive trends for language bursts and spelling) that generalized to other writing tasks (in this case writing essays).

However, two findings did not support this first set of hypotheses. For total words composed and total composing time, participants showed decreases following the intervention. One possible explanation is that the participants were simply tired, as in many cases students scheduled the post-test battery of normed language measures (Authors, 2016a, 2016b) on the same day as the post-test writing tasks (with the normed measures occurring first), leading to a much longer single session at the university (as compared to two separate sessions at pretest). The intervention $\times$ mode interactions for total words and total time support this explanation, as the decreases in text length and writing time were larger for stylus, which was more challenging for many of the participants.

\section{Second Hypotheses Tested and Significance}

The second set of hypotheses tested focused upon transcription mode, with predictions that students would compose longer texts when keyboarding, but with more pauses and shorter language bursts. These hypotheses were mostly supported, with one unexpected significant result. Consistent with Morphy and Graham's (2012) meta-analysis of weaker writers and word processing, students wrote more words, and for longer times, when keyboarding before and after the intervention, with effect sizes ranging from .34 (total words) to .24 (total time). These findings may be related to motivational factors, as some have reported that students prefer keyboarding to handwriting (see Berger \& Lewandowski, 2013), perhaps due to a more legible texts produced, more opportunities for revision, and less effortful letter production (Dauite, 1986). The mode $\times$ group interaction for total words suggests that keyboarding (letter selection) was especially beneficial for the students with dysgraphia, who by definition struggle with letter formation. Future research studies should examine the effects of specific kinds of keyboarding instruction upon language bursts and pauses for students with different kinds of transcription-related disabilities.

Predictions that students would compose in longer language bursts and make fewer pauses when writing by stylus were partially supported. Students had fewer pauses per minute when writing by stylus, with a large effect size (partial $\omega 2=.77$ ). For language bursts, only a trend was found favoring stylus ( $p=.068$ ). In a recent study (Beers et al., 2017), students composed in longer language bursts when writing narratives by stylus (vs. keyboarding). 
Although the finding for language bursts and stylus was not significant for essays, it is possible that the demands of writing essays, in contrast to narratives, influenced the length of language bursts, as students grappled with the syntactic (and perhaps vocabulary) demands of this genre.

One key difference between writing modes is that producing letters by stylus allows writers to view their letters and words more easily as they create them, which can help keep linguistic units active in working memory while also supporting translation and transcription processes (such as reviewing letters for legibility and words for spelling). The participants in this study were at a hunt-and-peck rather than a touch-typing stage of their keyboarding development. When students must look at their hands to select correct keys while composing, and then stop to review their emerging texts, more pauses are likely. Writers likely need to develop touch-typing skills to review their texts as they compose them while keyboarding, progressing from "keyboard gazers" when typing to "monitor gazers" (Johansson, Wengelin, Johansson, \& Holmqvist, 2010). An unexpected finding was found for percent of spelling errors, with fewer errors made when keyboarding. Although most word-processing software programs offer some type of spelling support ("spell check"), no software support for spelling was available to students when writing by keyboard for this study. Given the difficulties students with dyslexia (and to a lesser extent, students with dysgraphia) have with spelling (see Connelly \& Dockrell, 2016), this finding may have important implications. It is possible that the increased legibility of keyboarded text makes it easier to identify misspelled words, and the ease of making corrections when keyboarding leads to more corrections overall. More research is needed to explore this possibility.

\section{Comparisons with Typical Controls without SLDs-WL}

The process and product measures collected at posttest for students with dyslexia and students with dysgraphia were compared with the same measures gathered from a group of typically developing students in the same grade range, as another way to evaluate the effectiveness of the intervention. Most strikingly, the process measures of students with dysgraphia as they composed essays were not significantly different from those of the typically developing students; and when keyboarding, none of the process or product measures were significantly different. Given their difficulties with letter production when writing, it was not surprising that students with dysgraphia wrote fewer words, and for a shorter time, when writing by stylus. However, their rate of composing (words per minute) and their pause behaviors were not significantly different, and although their language bursts were shorter on average, these differences also were not significantly different. When keyboarding, students with dysgraphia did compose for a shorter time and wrote shorter texts, but these differences, along with each of the others (there was a trend for percent of spelling errors, $p=.062$ ), were not significantly different from the typical control. Although these results must be interpreted cautiously, they do suggest that keyboarding, in combination with a writing intervention similar to the one described here, may offer particular benefits to students with dysgraphia.

However, there were several significant differences between the students with dyslexia at posttest and their typically developing peers, especially when writing by keyboard. In this 
mode, students with dyslexia wrote shorter texts, made more spelling errors, and composed fewer words per minute (with a trend for shorter language bursts, $p=.058$ ). Despite these findings for product measures, pause behaviors (pause length, pauses per minute) were not significantly different for the dyslexia group and typical control group when writing essays. When writing by stylus, there were fewer differences, as only total words and percent of spelling errors were significantly different. These findings provide additional evidence that the intervention increased writing fluency for students with dyslexia, especially when writing by hand, despite persisting difficulties with spelling. Given that spelling problems tend to slow transcription processes (Sumner et al., 2013), any improvements in writing fluency are noteworthy. However, these findings for essay writing for students with dyslexia should be viewed cautiously until future research evaluates whether the results replicate.

\section{Limitations, Future Research Directions, and Conclusions}

Limitations-Results of the current study should be cautiously generalized only to students at the same grade levels during middle childhood or early adolescence whose dysgraphia or dyslexia is diagnosed in a comparable way, and who receive comparable instructional intervention based on levels of language. Also, the current sample size is relatively small. Nevertheless, the current results suggest promising directions for future research on on-line processes and products in the writing of students with transcription disabilities.

Future research directions-Research on language bursts, pauses and other on-line writing measures is increasing, but important questions remain unanswered as to how the on-line processing measures should be calculated. Most importantly, since language bursts are punctuated by pauses, how pauses are defined matters a great deal. In the majority of the research to date on pauses and language bursts, a two second pause threshold has been used (as in this study). However, a two second pause may be more appropriate for writers at specific fluency levels. As Sumner et al. (2013) demonstrated, pauses between $30 \mathrm{~ms}$ and two seconds appear to be sensitive to differences between children with dyslexia and children without dyslexia in the same grade range. When comparing across transcription modes, or perhaps even genres, pause thresholds may need to be tailored to specific writers engaging in specific writing tasks. Future research should examine the effects of different pause thresholds upon language bursts for writers at different fluency levels, in different transcription modes, and for different genres.

It is important to note that although the genre of the composing tasks is used frequently in school and was familiar to students, the topics of the essays were not necessarily ones in which all students were interested in or motivated to write about. We analyzed first drafts of these essays only, and although students could revise their texts during the writing session, they were not provided the opportunity to make further revisions after the single writing session. Due to this, suggestions about intervention effects upon spelling skills must be made cautiously, as the proportions of spelling errors calculated only reflects errors made on the first draft. Future research should explore online writing processes involved in revision of drafts, to provide windows into other aspects of skilled writing. 
Future research exploring transcription, language bursts, and writing fluency should also focus upon the specific effects of keyboarding instruction during middle childhood and early adolescence. For example, students who have and who have not been taught touch-typing could be compared. As students begin to learn keyboarding skills at younger and younger ages, understanding more about how this transcription mode can contribute to text production seems warranted.

Conclusions-Following an 18 session computerized intervention, students with persisting SLDs-WL during middle childhood and early adolescence (despite ongoing intervention) improved significantly in several on-line experimental measures reflecting the translation and transcription processes of writing. Their performance on some of these tasks at posttest was comparable to that of typically developing students who had completed the same on-line experiment. These findings provide hope that even students with persisting SLDs, who have not responded previously to writing instruction, may show improvement with specially designed interventions for students with SLDs-WL that target multi-leveled functional writing systems. Moreover, this study provides further evidence that technological tools have important applications not only for accommodations but also for writing assessment and instruction.

\section{References}

Abbott R, Raskind W, Matsushita M, Richards T, Price N, Berninger V. 2017; Dysgraphia, dyslexia, and OWL LD during middle childhood and early adolescence: Evidence for genetic effects on hallmark phenotypes. Biomarkers and Genes. 1(1):1-10. DOI: 10.15761/BG.1000103

Alamargot D, Chesnet D, Dansac C, Ros C. 2006; Eye and Pen: A new device to study reading during writing. Behavior Research Methods. 38:287-299. [PubMed: 16956105]

Alamargot, D, Dansac, C, Chesnet, D, Fayol, M. Parallel processing before and after pauses: a combined analysis of graphomotor and eye movements during procedural text production. In: Rijlaarsdam, C, Torrence, M, van Waes, L, Galbraith, D, editors. Writing and Cognition: Research and Applications. Vol. 20. Amsterdam: Elsevier; 2007. 13-29. Studies in Writing

Alves, RA, Branco, M, Castro, SL, Olive, T. Effects of handwriting skill, handwriting and dictation modes, and gender of fourth graders on pauses, written language bursts, fluency, and quality. In: Berninger, VW, editor. Past, present, and future contributions of cognitive writing research to cognitive psychology. New York, NY: Psychology Press; 2012. 389-402.

Alves, RA, Castro, SL, de Sousa, L, Strömqvist, S. Influence of typing skill on pause-execution cycles in written composition. In: Torrance, M, Van Waes, L, Galbraith, D, editors. Writing and cognition: Research and applications. Amsterdam, the Netherlands: Elsevier; 2007. 55-65.

Alves, RA, Castro, SL, Olive, T. Transcription skill constrains bursts of language production. In: Torrance, M, Alamargot, D, Castelló, M, Ganier, F, Kruse, O, Mangen, A, Tolchinsky, L, van Waes, L, editors. Learning to write effectively: Current trends in European research. Brussels: OPOCE; 2011.

Alves RA, Limpo T. 2013; Modeling writing development: Contribution of transcription and selfregulation to Portuguese students' text generation quality. Journal of Educational Psychology. 105:401-413.

Alves RA, Limpo T. 2015; Progress in written language bursts, pauses, transcription, and written composition across schooling. Scientific Studies of Reading. 19(5):1-18. DOI: 10.1080/10888438.2015.1059838

Alves RA, Limpo T, Fidalgo R, Carvalhais L, Pereira LA, Castro SL. 2016; The impact of promoting transcription on early text production: Effects on bursts and pauses, levels of written language, and writing performance. Journal of Educational Psychology. 108:665-679. DOI: 10.1037/edu0000089 
Barnett, A, Henderson, L, Scheib, B, Schulz, C. Detailed Assessment of Speed of Handwriting (DASH) Copy Best and Fast. London: Pearson; 2007.

Beers SF, Mickail T, Abbott R, Berninger V. 2017; Effects of transcription ability and transcription mode on translation: Evidence from written compositions, language bursts and pauses when students in grades 4 to 9 , with and without persisting dyslexia or dysgraphia, compose by pen or by keyboard. Journal of Writing Research. 9:1-25. DOI: 10.17239/jowr-2017.09.01.01 [PubMed: 30761210]

Beers SF, Nagy WE. 2009; Syntactic complexity as a predictor of adolescent writing quality: Which measures? Which genre? Reading and Writing: An Interdisciplinary Journal. 22:185-200.

Berger CL, Lewandowski L. 2013; The effect of a word processor as an accommodation for students with learning disabilities. Journal of Writing Research. 4(3):299-318. DOI: 10.17239/ jowr-2013.04.03.2

Berman RA, Nir-Sagiv B. 2007; Comparing narrative and expository text construction across adolescence: A developmental paradox. Discourse Processes. 43:79-120.

Berninger, VW. Interdisciplinary frameworks for schools: Best professional practices for serving the needs of all students. Washington, DC: American Psychological Association; 2015. Companion Websites with Readings and Resources and Advisory Panel. All royalties go to Division 16 to support these websites and develop future editions

Berninger, V, Hayes, JR. Twenty children on writing treks: Their developing self-regulated translation and related processes. In: Fayol, M, Alamargot, D, Berninger, V, editors. Translation of thought to written text while composing: Advancing theory, knowledge, methods, and applications. Psychology Press/Taylor Francis Group/Routledge; 2012.

Berninger V, Nagy W, Tanimoto S, Thompson R, Abbott R. 2015; Computer instruction in handwriting, spelling, and composing for students with specific learning disabilities in grades 4 to 9. Computers and Education. 81:154-168. DOI: 10.1016/j.compedu.2014.10.00NIHMS636683 [PubMed: 25378768]

Berninger V, Nielsen K, Abbott R, Wijsman E, Raskind W. 2008; Writing problems in developmental dyslexia: Under-recognized and under-treated. Journal of School Psychology. 46:1-21. DOI: 10.1016/j.jsp.2006.11.008 [PubMed: 18438452]

Berninger VW, Richards TL, Abbott R. 2015; Differential diagnosis of dysgraphia, dyslexia, and OWL LD: Behavioral and neuroimaging evidence. Reading and Writing: An Interdisciplinary Journal. 28:1119-1153. DOI: $10.1007 / \mathrm{s} 11145-015-9565-0$

Berninger V, Rutberg J, Abbott R, Garcia N, Anderson-Youngstrom M, Brooks A, Fulton C. 2006; Tier 1 and Tier 2 early intervention for handwriting and composing. Journal of School Psychology. 44:3-30. DOI: 10.1016/j.jsp.2005.12.003

Berninger, VW, Swanson, HL. Modifying Hayes and Flower's model of skilled writing to explain beginning writing and developing writing. In: Butterfield, EC, editor. Children's writing: Toward a process theory of development of skilled writing. Vol. 2. Greenwich, CT: JAI Press; 1994. 57-81.

Bourdin B, Fayol M. 1994; Is written language production more difficult than oral language production? A working memory approach. International Journal of Psychology. (5):591-620.

Chenoweth NA, Hayes JR. 2001; Fluency in writing: Generating text in L1 and L2. Written Communication. 18:80-98. DOI: 10.1177/0741088301018001004

Chenoweth NA, Hayes JR. 2003; The inner voice in writing. Written Communication. 20:99-118. DOI: $10.1177 / 0741088303253572$

Christensen C. 2005; The role of orthographic-motor integration in the production of creative and wellstructured written text for students in secondary school. Educational Psychology. 25:441-453.

Coleman C, Gregg N, McLain L, Bellair LW. 2009; A comparison of spelling performance across young adults with and without dyslexia. Assessment for Effective Intervention. 34:94-105. DOI: $10.1177 / 1534508408318808$

Connelly V, Dockrell J. 2016Writing development and instruction for students with learning disabilities: Using diagnostic categories to study writing difficulties. MacArthur CA, Graham S, Fitzgerald J. Handbook of writing research (2nd). :349-363.

Connelly V, Dockrell J, Walter K, Critten S. 2012; Predicting quality of composition and written language bursts from oral language, spelling, and handwriting skills in children with and without 
Specific Language Impairment. Written Communication. 29:278-302. DOI: $10.1177 / 0741088312451109$

Connelly V, Gee D, Walsh E. 2007; A comparison of keyboarded and written composition and the relationship with transcription speed. British Journal of Educational Psychology. 77:479-492. [PubMed: 17504558]

Crowhurst M, Piche GL. 1979; Audience and mode of discourse effects on syntactic complexity in writing at two grade levels. Research in the Teaching of English. 13:101-109.

Daiute C. 1986; Physical and cognitive factors in writing: Insights from studies in computers. Research in the Teaching of English. 20:141-159.

Goldberg A, Russell M, Cook A. 2003; The effect of computers on student writing: A meta-analysis of studies from 1992 to 2002. The Journal of Technology, Learning, and Assessment. 2:3-51.

Halliday, MAK, Hasan, R. Language, context, and text: Aspects of language in social-semiotic perspective. Geelong, VIC, Australia: Deakin University Press; 1985.

Hayes, JR. A new framework for understanding cognition and affect in writing. In: Levy, CM, Ransdell, S, editors. The science of writing: Theories, methods, individual differences, and applications. Mahwah, NJ: Lawrence Erlbaum Associate; 1996. 1-27.

Hayes, JR, Berninger, V. Cognitive processes in writing: A framework. In: Arfé, B, Dockrell, J, Berninger, V, editors. Writing development and instruction in children with hearing, speech, and language disorders. NY: Oxford University Press; 2014.

Hayes JR, Chenoweth NA. 2006; Is working memory involved in the transribing and editing of texts? Written Communication. 23(2):135-149.

Hayes JR, Chenoweth NA. 2007; Working memory in an editing task. Written Communication. 24:283-294. DOI: $10.1177 / 0741088307304826$

Hayes, JR, Flower, LS. Identifying the organization of writing processes. In: Gregg, L, Steinberg, E, editors. Cognitive processes in writing: An interdisciplinary approach. Hillsdale, NJ: Erlbaum; 1980. 3-30.

Johansson R, Wengelin A, Johansson V, Holmqvist K. 2010; Looking at the keyboard or the monitor: Relationship with text production processes. Reading and Writing: An Interdisciplinary Journal. 23:835-851.

Kaufer DS, Hayes JR, Flower L. 1986; Composing written sentences. Research in the Teaching of English. 20:121-140.

Kellogg RT. 2008; Training writing skills: A cognitive developmental perspective. Journal of Writing Research. 1:1-26.

Leijten M, Van Waes L. 2013; Keystroke Logging in writing research: Using Inputlog to analyze and visualize writing processes. Written Communication. 30(3):358-392. DOI: $10.1177 / 0741088313491692$

Limpo T, Alves RA. 2013; Modeling writing development: Contribution of transcription and selfregulation to Portuguese students' text generation quality. Journal of Educational Psychology. 105:401-413.

Mather, N, Roberts, R, Hammill, D, Allen, E. Test of Orthographic Competence (TOC). Austin, TX: Pro-Ed; 2008.

Morphy P, Graham S. 2012; Word processing programs and weaker writers/readers: A meta-analysis of research findings. Reading and Writing: An Interdisciplinary Journal. 25:641-678. DOI: 10.1007/ s11145-010-9292-5

Olive T, Kellogg RT, Piolat A. 2008; Verbal, visual and spatial working memory demands during text composition. Applied Psycholinguistics. 29(4):669-687. DOI: 10.1017/S0142716408080284

Puranik CS, Lombardino LJ, Altmann LJ. 2007; Writing through retellings: An exploratory study of language-impaired and dyslexic populations. Reading and Writing: An Interdisciplinary Journal. 20(3):251-272. DOI: $10.1007 / \mathrm{s} 11145-006-9030-1$

Sumner E, Connelly V, Barnett A. 2013; Children with dyslexia are slow writers because they pause more often and not because they are slow at handwriting execution. Reading and Writing: An Interdisciplinary Journal. 26:991-1008. 
Sumner E, Connelly V, Barnett A. 2014; The influence of spelling ability on handwriting production: Children with and without dyslexia. Journal of Experimental Psychology: Learning Memory and Cognition. 40(5):1441-1447. DOI: 10.1037/a0035785

Sumner E, Connelly V, Barnett A. 2016; The influency of spelling ability on vocabulary choices when writing for children with dyslexia. Journal of Learning Disabilities. 49:293-304. [PubMed: 25249592]

Tanimoto S, Thompson R, Berninger V, Nagy W, Abbott R. 2015; Computerized writing and reading instruction for students in grades 4 to 9 with specific learning disabilities affecting written language. Journal of Computer Assisted Learning. 31:671-689. DOI: 10.1111/jcal.12110 [PubMed: 26858470]

Van Waes L, Schellens PJ. 2003; Writing profiles: The effect of the writing mode on pausing and revision patterns of experienced writers. Journal of Pragmatics. 35:829-853.

Wanzek J, Vaughn S, Wexler J, Swanson EA, Edmonds M, Kim A. 2006; A synthesis of spelling and reading interventions and their effects on the spelling outcomes of students with LD. Journal of Learning Disabilities. 39:528-543. [PubMed: 17165620]

Wechsler, D. Wechsler intelligence scale for children. 4th. San Antonio, TX: The Psychological Corporation; 2003. (WISC-IV) 


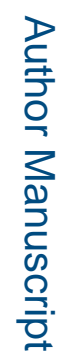

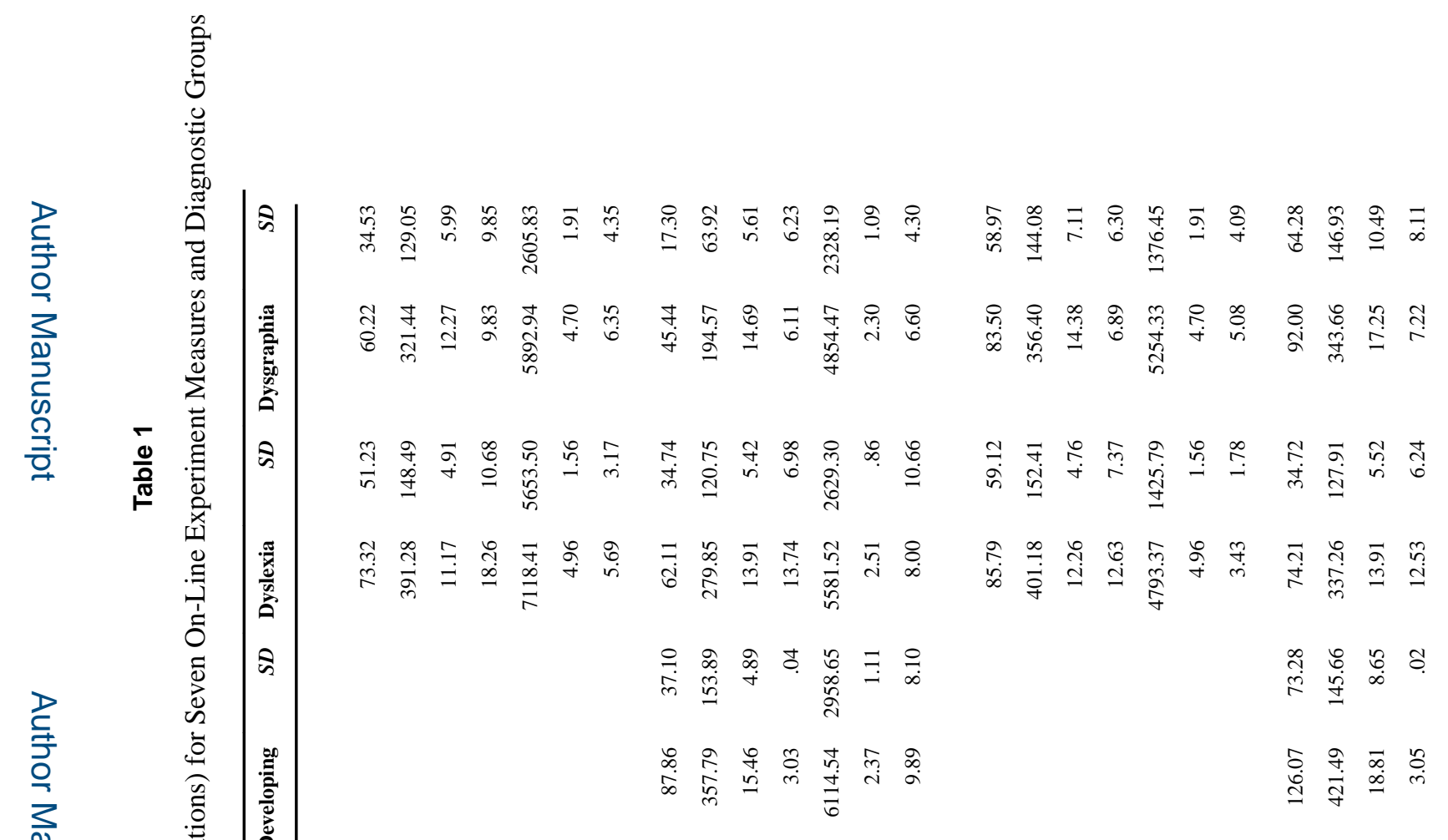

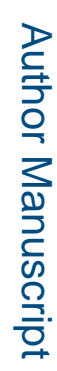

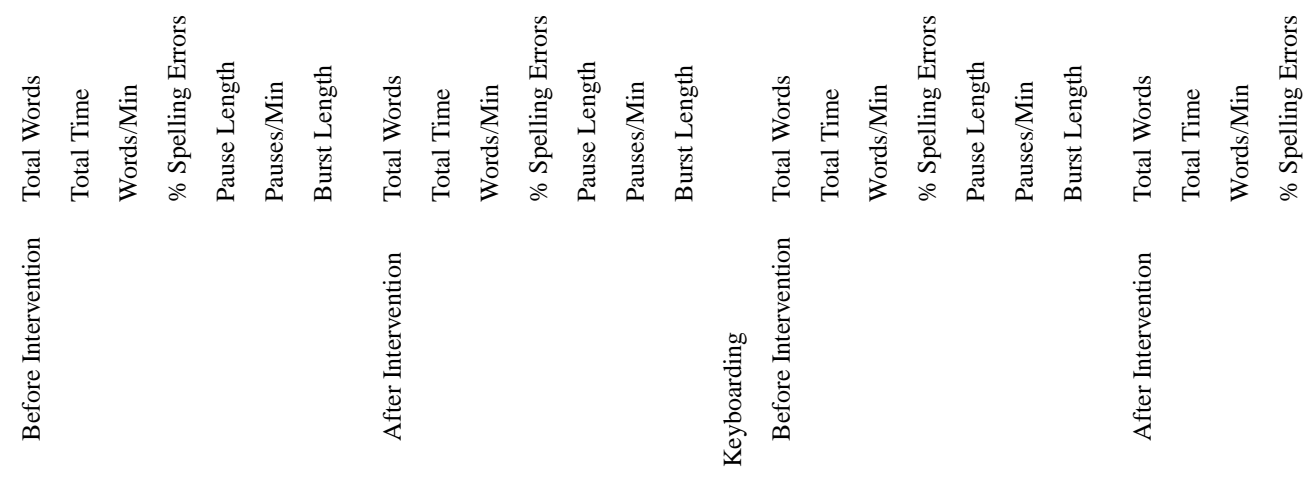




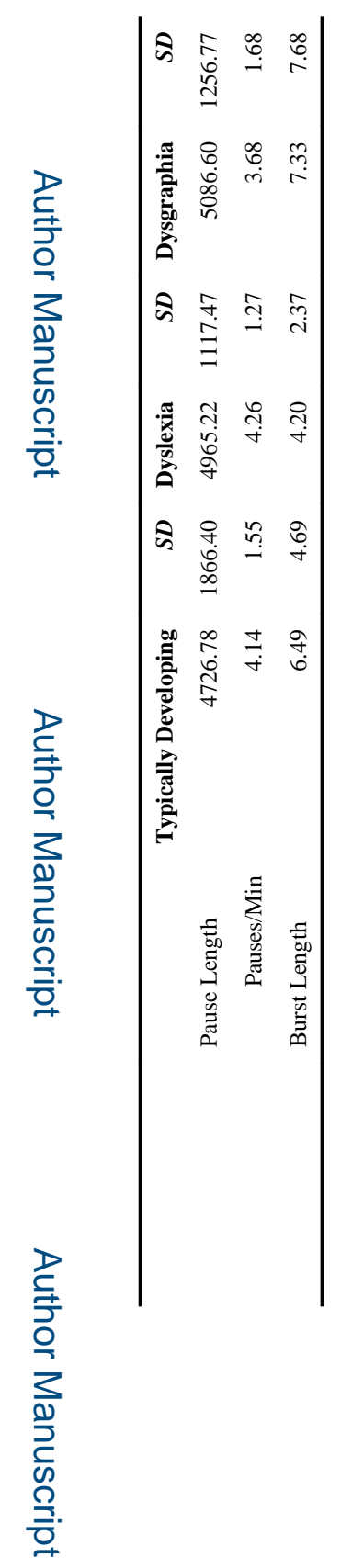

로을 


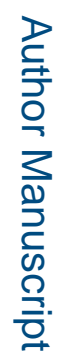

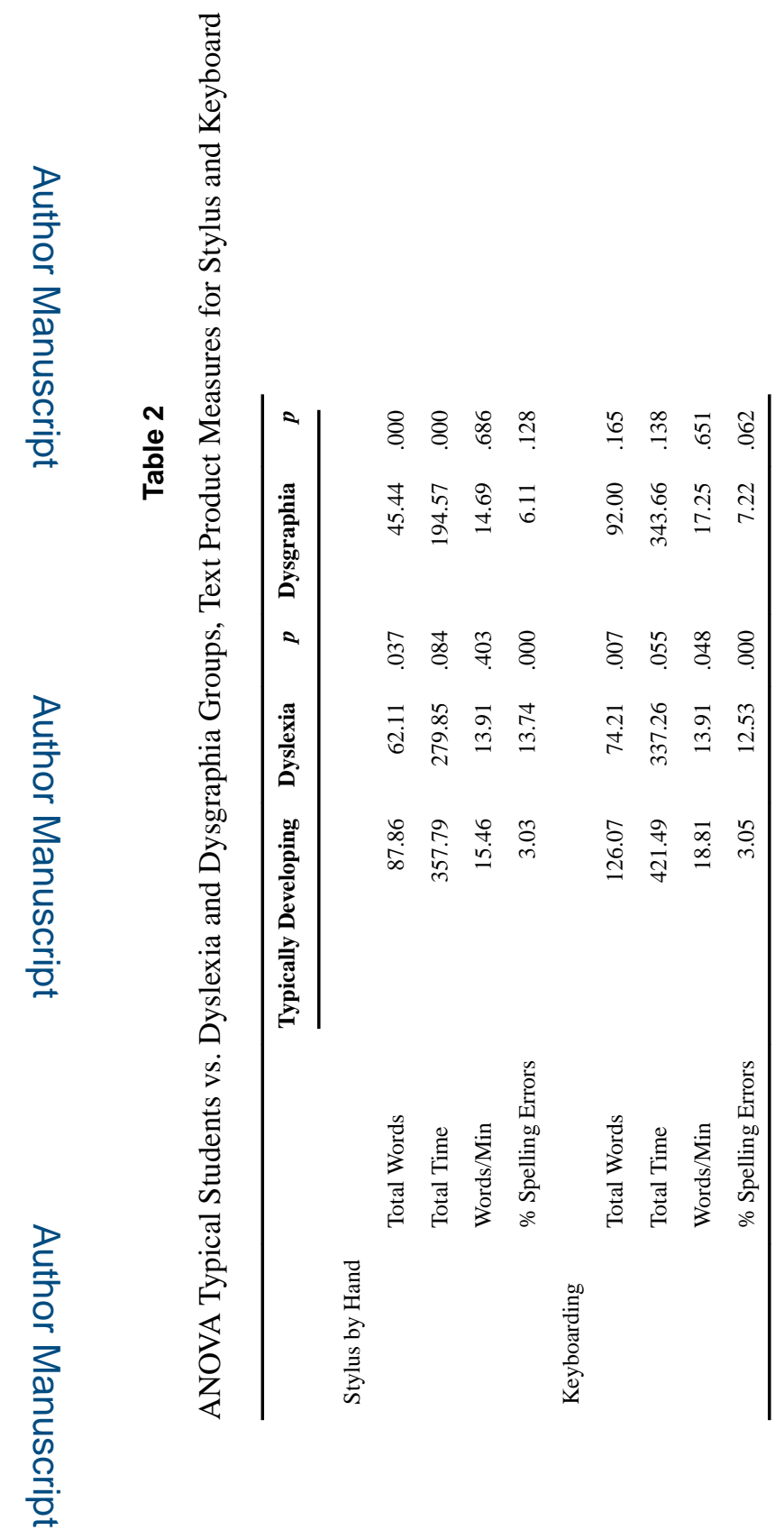




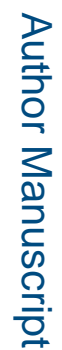

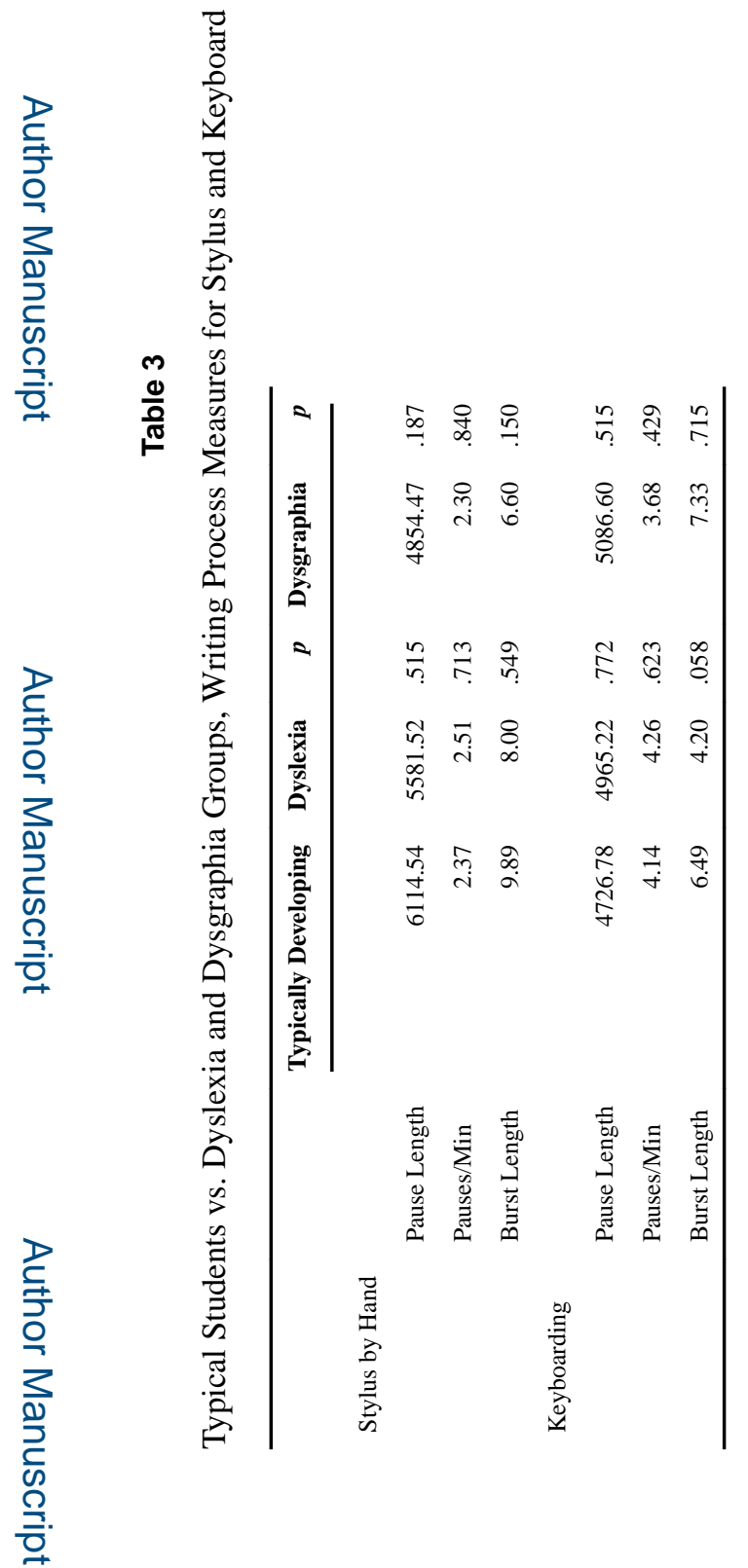

Learn Disabil. Author manuscript; available in PMC 2019 February 19. 